\title{
Potential food additive of Boswellia carterii essential oil encapsulated within gum arabic: a particle size distribution and zeta potential analysis
}

\author{
${ }^{1}$ Barre, M.S., ${ }^{1, *}$ Ali, F.B., ${ }^{2}$ Mirghani, M.E.S., ${ }^{2}$ Hazri, N.F., ${ }^{3}$ Anuar, H. and ${ }^{3}$ Nasir, N.A.M. \\ ${ }^{I}$ Department of Biotechnology Engineering, Kulliyyah of Engineering, International Islamic University \\ Malaysia (IIUM) Gombak Campus, P. O Box 10, 50728 KL, Malaysia \\ ${ }^{2}$ International Institute for Halal Research and Training, IIUM Gombak Campus. P. O Box 10, 50728 KL, \\ Malaysia \\ ${ }^{3}$ Department of Manufacturing and Materials Engineering, Kulliyyah of Engineering, International Islamic \\ University Malaysia (IIUM) Gombak Campus, P. O Box 10, 50728 KL, Malaysia
}

\section{Article history: \\ Received: 14 October 2019 Received in revised form: 15 January 2020 \\ Accepted: 17 January 2020 Available Online: 15 April 2020}

\section{Keywords:}

Boswellia carterii,

Essential oil,

Gum Arabic,

Microencapsulation,

Particle size

DOI:

https://doi.org/10.26656/fr.2017.4(S2).339

\begin{abstract}
Boswellia carterii (BC) \{Burseraceae family\} essential oil (EO) were extracted by hydrodistillation process. Gum Arabic (GA) \{Acacia senegal\} polymer particles containing a $B C E O$ were prepared by spray drying technique. The mean particle size and its distribution, as well as the zeta-potential of the microcapsules, were analyzed and found Z-Average $382 \pm 203 \mathrm{~nm}$, PDI $0.77 \pm 0.3$, ZP- $25 \pm 2.73 \mathrm{mV}$, respectively. Product encapsulation efficiency (EE \%) was found at $75 \pm 0.8 \%$. The surface morphology of the particles was obtained by scanning electron microscope (SEM). Furthermore, particles moisture content was analyzed by the oven drying method. The efficiency of encapsulation (EE \%) was estimated by specifying the content of essential oil in the product. Gas chromatography (GC) coupled with time-of-flight mass spectrometry (TOFMS) analysis of EO has been performed to determine the chemical compounds and their prevalence concentrations respectively. The composition of initial essential oil (added in the emulsion) and the encapsulated essential oil (extracted from spray dried powder) were analyzed and compared. The outcome of the research encourages the high potentiality and usefulness of the product in the food industries sector as a food additive agent, moreover, it suggests for further research to unravel potential implementation of BCEO microcapsules in the food production chain
\end{abstract}

\section{Introduction}

Essential oils are liquid secondary metabolites which synthesized by various organs of aromatic plants such as "leaves, flowers, rhizomes, seeds, stems, and plant exudates like gums and resins" (Andrade et al., 2014) and they have many interesting applications in Food, Cosmetic, and Pharmaceutical industries (Rao et al., 2019). However, these oils are highly concentrated volatile substances which are very sensitive to the surrounding environmental conditions "temperature, humidity, and oxygen" (Burt, 2004; Dubey et al., 2009; Kotronia et al., 2017).

Essential oils (EOs) had a tremendous shining history in the ancient times for their useful advantages, such as their nutraceutical properties and have gained a renewed interest recently because of their widely diversified applications and numerous relevant biological activities, which makes them more useful in different sects of industries (Elshafie and Camele, 2017). EOs are mostly extracted from several medicinal and aromatic plants by distillation method (Reyes-Jurado et al., 2014; Cui et al., 2017; Guan et al., 2019). Usually, they possess antioxidant, antimicrobial properties and used as food preservatives (Fathi et al., 2014; Preedy, 2016).

Hence, recently in food industries alone, many studies are showing the benefit of these natural products and their potentiality to replace artificial food additives such as flavoring and preserving agents (Fathi et al., 2014; Basak and Guha, 2018). Other industries also (pharmaceutical, cosmetic, textile) use EOs into their value-added products, which enhances and improves the consumer habit of adopting these newly improvised formulations (Carvalho et al., 2015; Sharifi-Rad et al., 2016).

Hence, to obtain these valuable volatile liquids from the plant matrix, different methods had been employed 
(Fahim et al., 2017). The extraction methods which had been used to get EOs from the plants kept on changing consistently over time. However, the most frequently used methods were; hydrodistillation, steam-distillation, organic solvent extraction, furthermore, recently have been added view more extraction techniques, such as; supercritical extraction, microwave extraction, ultrasonic extraction, Ohmic assisted extraction etc, depending on the plant species and plant organs to be extracted (Fahim et al., 2017; Gavahian and Farahnaky, 2018; Turk et al., 2018; Giacometti et al., 2018).

In the present study gum resin from BC were extracted by hydrodistillation process. The EO obtained was analyzed by GC-TOF-MS to determine its chemical composition and the predominant compounds. Hence, to get the full benefit of them, encapsulation techniques ensures the protection of the fragile oils and their controlled release to the desired target (Ahn et al., 2008). Moreover, it enhances the versatile formulations and diversified applications. Proper selection of coating materials and their concentration ratios is of the utmost importance for spray drying to obtain the required functional characteristics for the final product of microparticles.

Hence, the most commonly used carriers (coating/ wall materials) in micro and nanoencapsulation processes are polymers, gelatin, liposome and solid lipid nanoparticles (Wang, 2015). Thus, the main objectives in the present study summarized as follows; extraction of EO from BC gum resin by Hydro-distillation process and emulsifying them with Gum Arabic polymer particles as a carrier agent using deionized water. After homogenizing the emulsion properly, the spray drying process was performed to dry it and embedded EO into the Gum-Arabic polymer, subsequently, particle analysis and characterization were performed to determine their stability and size distribution.

\section{Materials and methods}

\subsection{Materials}

BC gum resin was obtained from Somaliland harvesters and identified botanically by botany department of Burco University, (Burco), whereas, gum Arabic (Acacia Senegal) purchased from Perfect Life Company (UAE). The primary solvent used in the experimental process was deionized water (DI W).

\subsection{BC Essential oil extraction}

To extract the essential oil from $\mathrm{BC}$ gum resin hydrodistillation process was employed. Clevenger type of distillation apparatus was used. Ratios 1:10 of gum to DI water were used in the distillation process. After separation of the EO from hydrosol, it was dried over anhydrous sodium sulfate to eliminate traces of moisture and stored in sealed vials at low temperature $\left(4^{\circ} \mathrm{C}\right)$ for further analysis. About $4 \pm 0.3 \%$ yield of $E O$ by weight was obtained from the process. The Essential oil was analyzed by Gas chromatography (GC) coupled with time-of-flight mass spectrometry (TOF-MS) to identify their chemical constituents. The electron impact $(70 \mathrm{eV})$ GC-MS measurement were performed with a Hewlett Packard 5890 II GC equipped with a HP-5 MS capillary column ( $30 \mathrm{~m} \mathrm{X} 0.25 \mathrm{~mm}$ i.d. $0.25 \mu \mathrm{m})$ and HP 5972 mass selective detector. A temperature was programmed to start initially from $80^{\circ} \mathrm{C}$, followed by the increase of $10^{\circ} \mathrm{C} / \mathrm{min}$ until reached up to $270^{\circ} \mathrm{C}$ with two minutes solvent delay by injection. The injector temperature was adjusted to $200^{\circ} \mathrm{C}$ for the analysis (Basar, 2005).

\subsection{Emulsion preparation}

Oil in water $(\mathrm{O} / \mathrm{W})$ emulsion preparation procedure is used, and a ratio of the different agents was EO $3 \mathrm{~g}$ : GA 27g: DI W 70g, respectively. Overnight mechanical agitation was used to homogenize the solution for better emulsion preparation.

\subsection{Spray drying process and particle analysis}

The BC EO and GA emulsion were dried by BUCHI mini spray dryer B-290. After obtaining the microencapsulated particles different characterization analyses were performed, namely: Particle size average (Z-Aver), Particle size distribution (PDI), and Zeta Potential (ZP) of the particles to determine their stability and interaction properties in the solution. Hence, flowing methods have been used:

a) For particle size distribution, Zeta potential, and polydispersity index determination, Zetasizer Ver. 7.01; manufactured by MALVERN, was used. System temperature was $25^{\circ} \mathrm{C}$, Count Rate $(\mathrm{kcps})$ was 135.7, and Cell description; Disposable sizing cuvette. The solution was sieved by Whatman No. 1 before analyzing it.

b) JOEL 6360LA scanning electron microscope (SEM) JEOL Ltd., Tokyo, JAPAN was used for elucidating the physical structure of BC EO microencapsulated in GA (Figure 2).

\section{Results and discussion}

The hydrodistillation process of extraction used here produced a considerably high yield $(4 \pm 0.3 \%$ by weight $)$ of EO, and their chemical properties were shown in (Table 1). The average standard yield usually obtained from this species is recorded to be $2.5 \%$ to $5 \%$ by weight, depending on various factors, including 


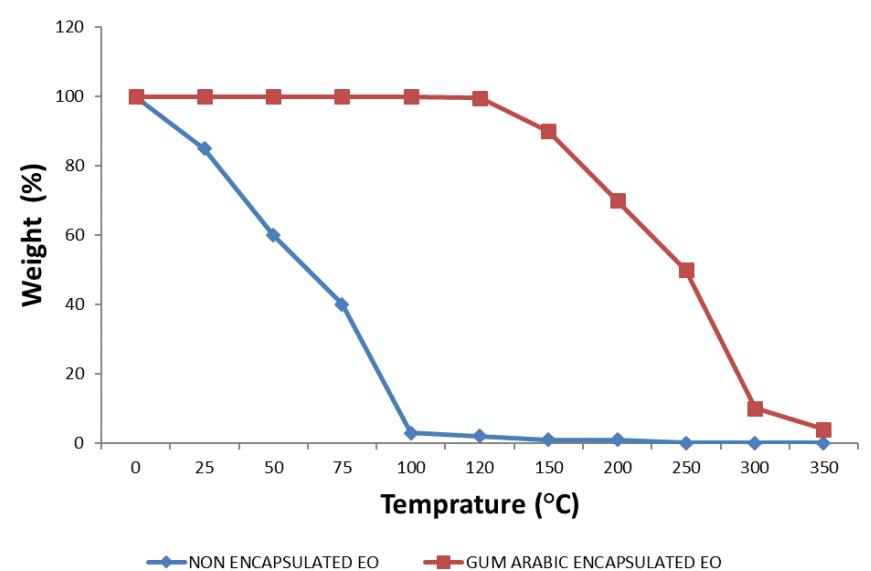

Figure 1.Thermo-gravimetric analysis (TGA,) of encapsulated $\mathrm{BC}$ EO with GA and non-encapsulated $B C E O$

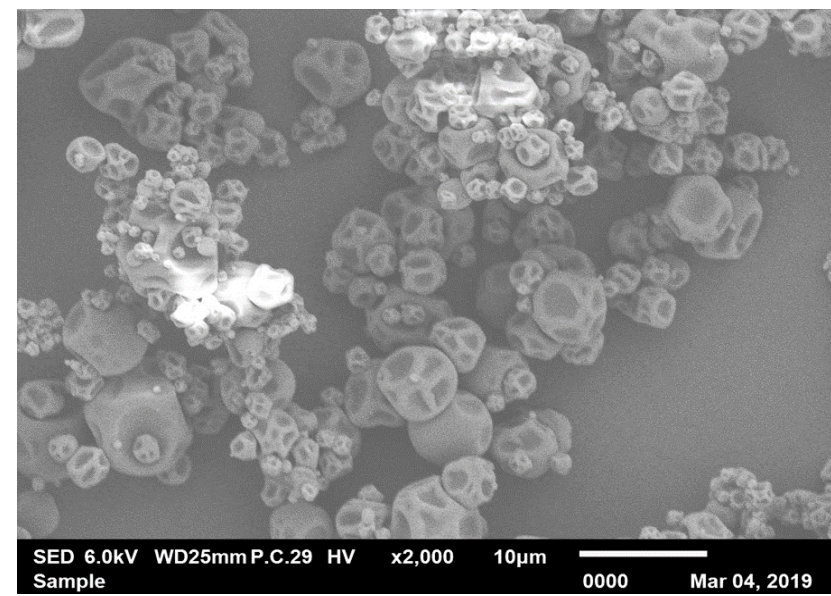

Figure 2. Scanning Electron Microscopy (SEM) analysis of particles

Table 1. Most abundant chemical compounds of BC EO before encapsulation

\begin{tabular}{|c|c|c|c|}
\hline No Compound name & Similarity & Area \% & Cas No. \\
\hline 1 (-)-Myrtenol & 827 & 1.7844 & 19894-97-4 \\
\hline 2 Naphthalene, 1,2,3,5,6,8a-hexahydro-4,7-dimethyl-1-(1-methylethyl)-, (1S-cis)- & 856 & 4.2162 & $483-76-1$ \\
\hline 3 Carveol & 860 & 12.622 & $99-48-9$ \\
\hline 4 Cyclohexene, 1-methyl-4-(1-methylethylidene)- & 865 & 1.1363 & $586-62-9$ \\
\hline 5 ç-Terpinene & 865 & 11.218 & $99-85-4$ \\
\hline 6 á-copaene & 867 & 3.1426 & $0-00-0$ \\
\hline 7 Bicyclo[3.1.1]hept-3-en-2-one, 4,6,6-trimethyl-, (1S)- & 871 & 1.8076 & 1196-01-6 \\
\hline 8 à-Phellandrene & 912 & 0.10367 & $99-83-2$ \\
\hline 9 1,3,6-Octatriene, 3,7-dimethyl-, (Z)- & 958 & 7.1806 & $3338-55-4$ \\
\hline
\end{tabular}

Table 2. Most abundant chemical compounds of BC EO after encapsulation

\begin{tabular}{llcc}
\hline No Compound name & Similarity & Area \% & Cas No. \\
\hline 1 Aromandendrene & 872 & 7.2737 & $539-52-6$ \\
2 Propanoic acid, 2-hydroxy-2-methyl-, ethyl ester & 883 & $9.01 \mathrm{E}-05$ & $123-35-3$ \\
3 á-Myrcene & 887 & 8.0539 & $98-55-5$ \\
4 à-Terpineol & 895 & 0.51593 & $470-82-6$ \\
5 Eucalyptol & 902 & 1.6146 & $80-56-8$ \\
6 à-Pinene & 907 & 4.485 & $3387-41-5$ \\
7 Bicyclo[3.1.0]hexane, 4-methylene-1-(1-methylethyl)- & 908 & 9.8309 & $3779-61-1$ \\
8 Cyclohexene, 1-methyl-4-(1-methylethenyl)-, (S)- & 929 & 7.9913 & $3387-41-5$ \\
9 Bicyclo[3.1.0]hexane, 4-methylene-1-(1-methylethyl)- & 934 & 9.8309 & $127-91-3$ \\
10 á-Pinene & 962 & 1.9445 & $535-77-3$ \\
11 Benzene, 1-methyl-3-(1-methylethyl)- & 962 & 4.9508 & $535-77-3$ \\
\hline
\end{tabular}

(harvesting time, storage process, and method of extraction).

The encapsulated particles obtained from the spray drying process have been analyzed from different aspects. Their TGA analysis (Figure 1) shows that the GA gave good protection to the $\mathrm{EO}$ and only started to degrade after $150^{\circ} \mathrm{C}$ of temperature, conversely, nonencapsulated EO started evading at ambient temperature and totally evaporated at $100^{\circ} \mathrm{C}$ of temperature). GCTOF-MS analysis of the EO before and after encapsulation shows no significant difference been detected in terms of chemical compounds (Table 1 and 2).
Size, zeta potential, and polydispersity index (PDI) of particles are considered important parameters for the characterization of particles. The Z-Average of particle size was almost $382 \pm 203 \mathrm{~nm}$, whereas, the zeta potential was found to be $-25.9 \pm 2.73 \mathrm{mV}$, which indicates the good stability of the particles. However, the PDI shows a broadly dispersed particle size (PDI $=0.77)$. Scanning electron microscope (SEM) as presented in Figure 2 shows semi-spherical tapered particle shape. Hence, optimizing of certain parameters such as the ratio of $\mathrm{EO}$ to GA polymer particles in the emulsion preparation could improve the particle size homogeneity and their physical structure also. Maqbool et al. (2011) analyzed 
the postharvest application of GA with and without Cinnamon and Lemon Grass EOs on some tropical fruits as a shelf life enhancer, they concluded that GA with EOs gave fruits high protection and prolonged their storage period, which is supporting the present research findings. Nurdin et al. (2019) used GA as a surfactant on the stability of water-based alumina nanoparticle suspension and concluded that when the concentration of GA increased (from $0.1 \%$ to $0.5 \%$ ) the zeta potential falls down (from $-25 \mathrm{mV}$ to $-36 \mathrm{mV}$ ). Hence, this could be explained that GA minimizes interaction between particles which in turn prevents the suspension from agglomeration.

\section{Conclusion}

BCEO is very volatile and highly sensitive to environmental conditions. However, after encapsulation in GA polymer, it becomes more stable and easily transportable, formulation and dosing also been enhanced, which enables the different industries (Food, Cosmetics, and Pharmaceutical) to incorporate it within their value-added products for versatile applications. Hence, to improve particle size distribution stability and physical structure of the particles, optimization of the experimental process conditions is needed, considering the GA and EO ratios important factor in the process.

\section{Conflict of Interest}

The authors have no conflict of interest to declare.

\section{Acknowledgments}

This work was financially supported by the Research Initiative Grant Scheme - Post-Doctoral Fellow (RIGSPDF) (RPDF18-010-0010) from International Islamic University Malaysia.

\section{References}

Ahn, J., Kim, Y., Lee, Y., Seo, E., Lee, K. and Kim, H. (2008). Optimization of microencapsulation of seed oil by response surface methodology. Food Chemistry, 107(1), 98-105. https://doi.org/10.1016/ j.foodchem.2007.07.067

Andrade, B.F., Barbosa, L.N. and Probst, I. (2014). Antimicrobial activity of essential oils. Journal of Essential Oil Research, 26(1), 34-40. https:// doi.org/10.1080/10412905.2013.860409

Basak, S. and Guha, P. (2018). A review on antifungal activity and mode of action of essential oils and their delivery as nano-sized oil droplets in food system. Journal of Food Science and Technology, 55 (12), 4701-4710. https://doi.org/10.1007/s13197-018
$-3394-5$

Basar, S. (2005) Phytochemical investigations on Boswelia species. Germany: University of Hamburg, $\mathrm{PhD}$ Dissertation.

Burt, S. (2004). Essential oils: their antibacterial properties and potential applications in foods-a review. International Journal of Food Microbiology, 94(3), 223-253. https://doi.org/10.1016/ j.ijfoodmicro.2004.03.022

Carvalho, I.T., Estevinho, B.N. and Santos, 1. (2015). Application of microencapsulated essential oils in cosmetic and personal healthcare products - a review. International Journal of Cosmetic Science 38(2), 109-119. https://doi.org/10.1111/ics.12232

Cui, Q., Wang, L.T., Liu, J.Z., Wang, H.M., Guo, N., $\mathrm{Gu}, \mathrm{C} . \mathrm{B}$. and $\mathrm{Fu}$, Y.J. (2017). Rapid extraction of Amomum tsao-ko essential oil and determination of its chemical composition, antioxidant and antimicrobial activities. Journal of Chromatography B. 1061-1062, 364-371. https://doi.org/10.1016/ j.jchromb.2017.08.001

Dubey, R., Shami, T.C. and Rao, K.B. (2009). Microencapsulation technology and applications. Defence Science Journal, 59(1), 82-95. http:// doi.org/10.14429/dsj.59.1489

Elshafie, H. and Camele, I. (2017). An Overview of the Biological Effects of Some Mediterranean Essential Oils on Human Health. BioMed Research International, 2017, 1-14. https:// doi.org/10.1155/2017/9268468.

Fahim, M., Shrivastava, B., Shrivastava., A. K., Ibrahim, M., Parveen, R. and Ahmad, S. (2017). Review on extraction methods, antioxidant and antimicrobial properties of volatile oils. Annals of Phytomedicine 6 (2), 5-46. https://doi.org/ 10.21276/ap.2017.6.2.2

Fathi, M., Martín, A. and McClements, D.J. (2014). Nanoencapsulation of Food Ingredients using Carbohydrate Based Delivery Systems. Trends in Food Science and Technology, 39(1), 18-39. https:// doi.org/10.1016/j.tifs.2014.06.007

Gavahian, M. and Farahnaky, A. (2018). Ohmic-assisted hydrodistillation technology: A review. Trends in Food Science and Technology, 72, 153-161. https:// doi.org/10.1016/j.tifs.2017.12.014

Giacometti, J., BursaćKovačević, D., Putnik, P., Gabrić, D., Bilušić, T., Krešić, G., Stulić, V., Barba, F.J., Chemat, F., Barbosa-Cánovas, G. and Jambrak, A.R. (2018). Extraction of bioactive compounds and essential oils from Mediterranean herbs by conventional and green innovative techniques: A review. Food Research International, 113, 245262. https://doi.org/10.1016/j.foodres.2018.06.036. 
Guan, X., Ge, D., Sen, L. S., Huang, K., Liu, J. and Li, F. (2019). Chemical Composition and Antimicrobial Activities of Artemisia argyi Lévl. et Vant Essential Oils Extracted by Simultaneous DistillationExtraction, Subcritical Extraction and Hydrodistillation. Molecules, 24(3), 483. https:// doi.org/ 10.3390/molecules24030483.

Kotronia, M., Kavetsou, E., Loupassaki, S., Kikionis, S., Vouyiouka, S. and Detsi, A. (2017). Encapsulation of Oregano (Origanum onites L.) Essential Oil in $\beta$ Cyclodextrin ( $\beta-\mathrm{CD})$ : Synthesis and Characterization of the Inclusion Complexes. Bioengineering, 4(3), 74. http://doi.org/10.3390/bioengineering4030074

Maqbool, M., Ali, A., Alderson, P.G., Mohamed, M.T.M., Siddiqui, Y. and Zahid, N. (2011). Postharvest application of gum Arabic and essential oils for controlling anthracnose and quality of banana and papaya during cold storage. Postharvest Biology and Technology, 62, 71-76. https://doi.org/10.1016/ j.postharvbio.2011.04.002

Nurdin, I., Zulkifli, Satriananda and Nurlaili (2019). The Study of Gum Arabic as Surfactant on the Stability of Water-based Alumina Nanoparticle Suspensions. IOP Conference Series: Materials Science and Engineering, 536, 2086. htt://doi.org/10.1088/1757$899 X / 536 / 1 / 012086$

Preedy, V. (2016). Essential oils in food preservation, flavor and safety. $1^{\text {st }} \mathrm{ed}$. UK: Academic Press. https://doi.org/10.1016/C2012-0-06581-7

Rao, J., Chen, B. and McClements, D. (2019). Improving the Efficacy of Essential Oils as Antimicrobials in Foods: Mechanisms of Action. Annual Review of Food Science and Technology, 10(1), 365-387. http://doi.org/10.1146/annurev-food-032818121727

Reyes-Jurado, F., Franco-Vega, A., Ramírez-Corona, N., Palou, E. and López-Malo, A. (2014). Essential Oils: Antimicrobial Activities, Extraction Methods, and Their Modeling. Food Engineering Reviews, 7(3), 275-297. https:// doi.org/10.1007/s12393-014-90992

Sharifi-Rad, J., Sureda, A., Tenore, G., Daglia, M., Sharifi-Rad, M., Valussi, M., Tundis, R., SharifiRad, M., Loizzo, M.R., Ademiluyi, A.O., SharifiRad, R., Ayatollahi, S.A. and Iriti, M. (2017). Biological Activities of Essential Oils: From Plant Chemoecology to Traditional Healing Systems. Molecules, 22(1), 70. http://doi.org/ 10.3390/molecules22010070.

Turk, M., Mathe, C., Fabiano-Tixier, A., Carnaroglio, D. and Chemat, F. (2018). Parameter optimization in microwave-assisted distillation of frankincense essential oil. Comptes Rendus Chimie, 21(6), 622627. https:// doi.org/10.1016/j.crci.2018.03.001
Wang, B. (2015). Development of spray drying technology for microencapsulation of bioactive materials. Alabama, USA: Auburn University, PhD Dissertation. 